\title{
LOS JUDÍOS DE BELORADO Y SUS CONTORNOS
}

\author{
INOCENCIO CADIÑANOS BARDECI
}

I. Belorado, paso entre Castilla y la Rioja: el camino militar, coMERCIAL Y DE PEREGRINOS

Belorado aparece mencionado por primera vez a mediados del siglo $\mathrm{X}$ con el nombre de Bilforato, que viene a significar "Villa horadada".

El pueblo se encuentra en un cruce de caminos que se dirigen desde el Oeste (Burgos) al Este (Rioja y Navarra) y desde el Norte (Briviesca y Merindades) hasta el Sur (Salas de los Infantes), en todos los cuales tendrán, posteriormente, subidos intereses los condestables, duques de Frías.

Como villa fronteriza, nació a causa de la guerra y para vigilar el camino que unía Navarra y la Rioja con Castilla. Belorado se convierte, así, en llave o puerta del control de Burgos y su comarca más oriental o, como dicen las Crónicas, era "el fin del condado». $\mathrm{Su}$ emplazamiento al pie del desfiladero de los Montes de Oca dio lugar a que su nombre fuera sinónimo de "agujero para la guerra", puesto que "desde su sitio hay una cañada o agujero para ir a Rioja y Navarra".

Curiosamente su primera potenciación (concesión del fuero) le vino con el matrimonio y guerras civiles habidos entre doña Urraca y Alfonso el Batallador. Su desaparición como importante punto estratégico coincidiría con otro matrimonio, el de los Reyes Católicos, puesto que los frecuentes enfrentamientos entre sus respectivos reinos desaparecen para siempre tras su boda. Ambos hechos son simultáneos, también, con el inicio y fin de la presencia judía en nuestro pueblo '.

${ }^{\prime}$ F. Blanco Garcia, Belorado en la Edad Media. Catalogación de documentos medievales de la Rioja burgalesa, Madrid 1973. H. LOPEZ BERNAL, Apuntes históricos de Belorado, Estepa 1907. J. ORTEGA Galindo, «Belorado: Estudio de una villa en là Edad Media", Estvdios de Devsto II (1954) 141-188. 
A la importancia estratégica viene a sumarse la concurrencia de peregrinos que se dirigen a Santiago. El camino y sus puentes serán conservados eficazmente por dos santos: Domingo de la Calzada y Juan de Ortega.

La actividad comercial es una consecuencia lógica. A su calor acuden los judíos. En el fuero se fija como día de mercado el lunes, y el día de San Miguel será la feria anual. El mismo documento habla de pobladores "francos y castellanos". Poco después el cartulario de Bujedo nos cita a Marsinot de Sagrera y Francus de Belorado que confirman dicha presencia. En los siglos posteriores diversos privilegios reales apoyan a sus comerciantes. En el siglo XIV, por ejemplo, la villa estaba exenta de pagar portazgo en casi todo el reino, lo que revela una intensa actividad de sus pobladores. Y los documentos se hacen, además, extensivos no sólo a los cristianos sino también a judíos y moros, lo que evidencia la actividad e importancia comercial de estas dos comunidades.

\section{JUdíOS EN BELORADO}

\section{Las primeras noticias}

La presencia judía en los contornos de Belorado es temprana, contemporánea, quizá, a la aparición de la propia villa. En efecto, en 1028 se cita a un tal Sablevi o Scablevi, dueño de Grisaleña, Vallarta y también Terrazas, desaparecida aldea junto a Belorado. Se ha supuesto, con bastante probabilidad, que el tal Sablevi pudiera ser judío, señor de una gran propiedad.

Con mayor seguridad, y ya referente a la propia Belorado, la presencia judía se descubre en el año 1049 cuando aparece un nombre tan típico de los hebreos como es "Vitas de Villa foratu", aunque con toda evidencia sólo son citados los judíos por primera vez en el fuero de Alfonso I de Aragón (año 1116):

"et iudeo cum christiano et christiano ad iudeo qualem liborem fecit, talem pectet» ${ }^{2}$.

\footnotetext{
2 A. Ubieto Arteta, Cartulario de San Millán de la Cogolla, Valencia 1976, nos 186 y 259 .
} 
Durante el reinado de Fernando III los poderosos Lara atacaron y arrasaron Belorado y con toda seguridad la judería sufriría gravemente sus consecuencias. Pero es sabido que su hijo Alfonso $\mathrm{X}$ se interesó personalmente en repoblar nuestra villa, protegiendo a los hebreos. Por entonces aparece entre unos testigos un tal Rabi Çag de Belforado.

En 1429 Belorado pasaba a poder de los Velasco. Este hecho será decisivo en la historia local judía y su consiguiente prosperidad, puesto que siempre fueron los condestables protectores de los hebreos de quienes se servirían, sobre todo, en el aspecto fiscal. Por estos mismos años, tanto la aljama de Belorado como las demás de la provincia estaban dirigidas por el rabino mayor, Salomón Ha Leví, famoso judeoconverso que llegaría a ser obispo de Burgos.

\section{Los medios de vida: la actividad comercial y prestamista}

Los hebreos fueron propietarios de diversos bienes inmuebles como, por ejemplo, tierras, viñas y casas. A mediados del siglo XIV cierto testamento nos habla de una viña lindante con una finca de don Arsento, judío. Otra tenía por surquero a Juzel Alathar. El año anterior a la expulsión, un documento de la catedral burgalesa constata la venta de unas casas hecha a favor de Mose Bael, vecino de Belorado, que antes fueron de Salamon Avive, por 9.000 maravedís. Pocos años después el Consejo Real emplazaba a don Luis de Velasco, señor de la villa, para que restituyera a Juan Martínez de Valgañón y a sus sobrinos, judíos conversos, unas casas que poseían en Belorado en el tiempo de la expulsión ${ }^{3}$.

Ya se dijo que precisamente en la concesión del mercado, a principios del siglo XII, es cuando por primera vez aparecen los judíos. En relación con este mercado local y con el comercio en general es en donde más a menudo se nota su actividad.

En 1301 la comunidad sufre un duro golpe cuando Fernando IV ordena que ningún judío de la villa o sus aldeas pueda entrar el día de mercado (el lunes) a comprar en él. De lo que parece deducirse que también venían de fuera, puesto que el mercado de Belorado era redistribuidor de mercancías y los israelitas actuaban a modo de

${ }^{3}$ R.G.S: T. XII, $n^{2}$ 3.227. En 1478 aparece como propietario de cierta finca un tal Sansón, seguramente judío. 
buhoneros. Al mismo tiempo el monarca mandaba que se les juzgase apartadamente y que cumplieran con el gravamen de conservar perfectamente la torre del castillo.

Pero, como en tantas otras ocasiones, unos años después debió de ser palpable la decadencia del mercado y se suavizó la primera de estas órdenes. Efectivamente, en 1325 se les prohibe comerciar normalmente con los cristianos "porque los dichos judíos hacían muchos fraudes y bellaquerías", aunque sí podrían hacerlo en los mercados de los lunes ${ }^{4}$. Ocho años después, Alfonso XI daba al mercado local el carácter de franco en recompensa de que

"estando destruida y quemada esta villa en vida del señor rey don Sancho, la tomaron y poblaron y la defendieron a su costa».

De la nueva franquicia no se beneficiarían las clases marginadas del lugar:

«en tanto que los moros ni judíos de la dicha villa no puedan vender ni comprar en el dicho mercado"s.

Una de sus actividades se concretó en la compra-venta de vino, como consta que también lo hicieron sus hermanos de religión en Aranda de Duero y Medina de Pomar ${ }^{\circ}$. En 1334 volvía a prohibirse a todos los vecinos meter vino de fuera (riojano). Posiblemente no fue cumplida nunca rigurosamente la orden, y se recurrió a un fácil contrabando, del que participaron los judíos. Una sentencia arbitral de 1470 obligaba a los eclesiásticos a contribuir en las costas causadas en el pleito, que se seguía con aquéllos, sobre el vino que podían meter en la villa.

También se dedicaron al comercio exterior, lejos del pueblo. En 1311 el rey libraba a los vecinos, incluidos judíos y moros, de pagar

\footnotetext{
${ }^{4}$ B.N: Ms. 712, fol. 327 y Ms. 834, fol. 244v. De estos manuscritos copiaron y publicaron las noticias referentes a judíos, F. FITA, «La aljama hebrea de Belorado. Documentos históricos", BRAH XXIX (1896) 338-345. L. HUIDOBRO - F. CANTERA, "Juderías burgalesas (Beleña, Belorado)", Sefarad XIII (1953) 35-60 y L. SALAZAR Y Castro, Colección, O-16, fol. 396 a 410v.

${ }^{5}$ F. FITA, "La aljama», $n^{2} 3$.

6 I. Cadiñanos BardeCl, "Judios y moros en Aranda de Duero y sus contornos", Sefarad L (1990) 47-66 y "Judería y morería en Medina de Pomar», Sefarad XLV (1985) 237-280.
} 
portazgo y alcabalas en todo el reino, a excepción de Toledo, lo que evidencia el amplio radio de acción del comercio de los de Belorado.

Como en todas las demás ciudades españolas en que residieron colonias judías, también en Belorado los judíos destacaron como recaudadores y prestamistas.

En cierto itinerario inglés de fines del siglo XIV se asegura que los judíos eran señores de la comarca, a quienes había que pagar tributos para pasar por ella. Prescindiendo de su exageración, refleja una de sus más típicas actividades a través de los siglos, el cobro de impuestos ?.

El paso del camino de Santiago por Belorado fue aprovechado por los israelitas para ejercer su vocación cambista, prestamista, comercial y recaudadora.

En 1283 el poderoso don Lope Díaz de Haro debía de considerarse señor de Belorado, puesto que en dicho año fijaba la contribución que el concejo tenía que pagar en concepto de marzazga. Unos años después nos relata la crónica real cómo entabla pleito con Sancho IV, representados ambos por los judíos Abrahán el Barchilón y Simuel de Belorado, éste en nombre del monarca. El obispo de Astorga daría la razón al último. Instigado por Barchilón, don Lope reaccionaría de forma violenta amenazando de muerte al prelado. Curiosamente don Simuel también fue recaudador de dicho conde, como recordaba en cierta declaración de 1294:

"dixo que el que cogiera algunas veces dineros en la tierra de las fonsaderas que dauan al rey en el obispado de Burgos paral conde don Loppe» ${ }^{8}$.

El enfrentamiento mencionado acabaría trágicamente con la ejecución del favorito a manos del propio rey, en Alfaro. El popular Libro del Buen Amor lo recuerda al localizar a doña Loba (sinónimo de don Lope y del no muy claro proceder del judío) diciendo "que mora en Vilforado".

Aunque con no toda seguridad, este don Simuel de Belorado debió de ser el mismo que ejerció de almojarife del heredero, el Infante don Fernando. Su conducta no debió de ser recta:

7 F. Blanco Garcia, Belorado, pág. 20.

${ }^{8}$ M. Gaibrois, Sancho IV de Castilla, Madrid 1928, pág. 70. 
"este judio don Samuel era muy desamado de todos los de la tierra e de los de casa del rey, ca metia al rey como era moço en muchas cosas malas e era atrevido mucho" 9.

En todo caso nuestro recaudador intervino activamente en cuestiones económicas figurando en la distribución de Huete. El hecho de titularse «don" muestra cierta consideración social. En 1294, por ejemplo, no sólo aparece como recaudador en la provincia de Soria sino que interviene en negociaciones políticas con Aragón por mandato real ${ }^{10}$.

Entre los recaudadores que en 1367 acuden a hacer cierta pesquisa a Albelda (Logroño) aparece el alcalde de Belorado y don Çag Goey judío de Burgos, cogedores de monedas y servicios. Exactamente veinte años después aparecen

«Raby Mose Vziel, vezino de Velforado e Bienbeniste de Burgos iudios recabdadores de las terçias de las eglesias del dicho nuestro obispado [de Calahorra]"

poniendo demanda a los clérigos de Albelda, aunque no se accedió a su petición ".

De la actividad prestamista hebrea también poseemos abundantes noticias. En 1303 la aljama acuerda no cobrar, en adelante, personalmente sus crétidos sino hacerlo por medio de las autoridades municipales con el fin de evitar toda usura o engaño y también para asegurar el cobro de las mismas a su debido tiempo.

A las Cortes de Valladolid, de 1325, asistieron como procuradores dos vecinos de Belorado. En su archivo constan las peticiones generales que se presentaron, entre otras

"y de las deudas que los christianos debian a los judios se remitiese la tercia parte y por todo lo demas se les conzediese la espera de diez y ocho meses sin pagar usuras de ello en este tiempo por los muchos engaños que los christianos abian rezibido de los judios y porque se allaban muy pobres a causa de los grandes robos y males que abia habido y de la esterilidad de los años».

9 Ibid., pág. 71.

10 Ibid., pág. 70 y B.N: Ms. 13.090 .

1 E. SAINZ RIPA, Colección diplomática de las colegiatas de Albelda y Logroño, Logroño 1981, I, nos 212 y 242. 
Así lo concedió el rey para todo el reino, pero del hecho de que junto a otras concesiones conste ésta en el archivo de forma muy clara, podría deducirse que en Belorado el problema usurario era especialmente grave.

Con ocasión de las luchas fratricidas entre Enrique II y Pedro I, Belorado se convierte en un punto clave $\mathrm{y}$ es recorrido por uno y otro bando a merced de las circunstancias. La posesión de la corona se dirimió, en buena parte, en estas tierras. Es sabido que, mientras que los judíos fueron protegidos por Pedro I, serían, por el contrario, fieramente perseguidos por Enrique II. La judería de Burgos, por ejemplo, fue casi totalmente destruida por entonces. Es de suponer que otro tanto le ocurriera a la de nuestra villa.

En 1366 Enrique II entregaba la villa a su hermano Sancho. Fue éste un año trágico para el pueblo

"por quanto estades muy pobres e menesterosos por el gran daño que vos vino en la entrada que nos fecimos en que perdistes todo el mueble que abiedes, e por quanto murieron muchos homes de los vezinos de esa dicha villa".

Con el fin de ayudar a su recuperación, cinco años después confirmaba sus fueros, costumbres y privilegios y libraba a los vecinos de las deudas que tuvieran con los judíos, prorrogando las restantes (cristianas) por espacio de diez años

"e entre tanto que non corran penas ni logro contra vos, ni contra alguno ni ninguno de vos» 12 .

Pero unos años después aparecen las quejas por parte de estos últimos. Fue necesario ordenar que, si por razón de sus deudas

«se les abia prendado y tomado algunos bienes, que se los hiziesen restituir y boluer libremente».

También algunos judíos trataron de cobrar las suyas, amparados en ciertas cartas reales. Pero se confirmó lo arriba mandado

12 F. Blanco García, Belorado, pág. 74, nº 36. 
"sin embargo de las cartas que algunos de los dichos judíos abian ganado para que se les hiziese pago de sus deudas" ${ }^{13}$.

Como puede verse, la villa debía de encontrarse en graves apuros económicos puesto que, además de los hebreos, también era practicado el préstamo (seguramente con interés $y$, quizá, con usura) por los propios cristianos que lo tenían prohibido.

A mediados del siglo XV el cabildo catedralicio burgalés facultaba a cierta persona para cobrar los maravedís que le adeudaban unos vecinos de Belorado y, también, la judería. A fines del mismo, los judíos de Burgos serán los encargados de recoger las rentas del cabildo en las cuatro iglesias de Belorado y otras del contorno.

Pero los israelitas de la villa tuvieron también otras dedicaciones. En 1317 Alfonso XI facultaba a todos los habitantes de Belorado, incluidos moros y judíos, para poder cazar y pescar en los reales sitios, con excepción de algún punto muy concreto. Un documento de 1408 resume la sentencia por la que se permitía a la judería poder pastar sus rebaños ${ }^{14} \mathrm{y}$ cortar leña en los montes comunales, mientras que cumplieran con su obligación de reparar las murallas y el castillo. Es posible que el acopio de madera tuviera no sólo un uso particular sino también el destinado a la reparación mencionada y quizá, incluso, a su comercialización.

También es posible que se dedicaran, como ocurrió en otras partes, a la industria textil ${ }^{15}$.

\section{Exenciones, obligaciones e impuestos}

Ya se ha citado el privilegio de que gozaron, tanto los vecinos cristianos como judíos y moros de Belorado, de no pagar portazgo,

13 J. Ortega Galindo, "Belorado", pág. 168.

14 Consta que en 1498 había unas 4.000 cabezas de ganado menor, no pudiendo tener cada vecino más de 200 , según cierta sentencia. A ello habría que sumar el ganado mayor, lo que quizá produjo una cierta saturación por su alto número.

${ }^{15}$ Podría considerarse una manifestación de lo dicho cierto documento de Simancas de fines del siglo XV, en el que se informa a los Reyes Católicos de la situación de la industria textil de la región; en él se dice entre otras cosas: «En tierra de Burgos y en Ezcaray y Velorado y Valdelaguna y Neyba (Neila) con toda la serrania ... labraban paños desenos y dosenos verbis que son paños de gran baratura y de gran cuerpo de que mucha gente se sostiene...». 
ni montazgo, ni cuezas, ni alcabalas, ni ronda... en parte alguna del reino, a excepción de Toledo, otorgado a comienzos del siglo XIV.

En 1301 el rey Fernando IV ordenaba a la aljama que tuviera especial cuidado con la torre del homenaje de la fortaleza, para que no la dejasen caer, so pena de su merced. Posteriormente se le agregarían otras obligaciones más humillantes. Una interesante sentencia de 1408 narra cómo Ayn Meromat en nombre de los demás judíos se había quejado de que la villa y sus justicias los apremiaban a que barriesen las calles y plazas y reparasen las murallas que bajaban desde la torre del homenaje hasta el arco de doña Blanca y no les dejaban pacer con sus ganados ni cortar leña en los montes. Se juntó el concejo y, como diputados por la aljama, acudieron el citado Ayn Meromat y don Carrued y Ben Tropabe. La sentencia ordenó que cada semana nombraran los judíos dos personas que barrieran calles y plazas los jueves, que corriera a su cargo el reparo del mencionado lienzo de las murallas y torre del homenaje y que pudieran apacentar sus ganados y cortar leña ${ }^{16}$. Al mismo tiempo, y debido a lo gravoso de las obras de la muralla, el rey confirmaba otro privilegio de su padre por el que mandaba a los recaudadores de los pechos de las aljamas de la Bureba y la Rioja que no lo hicieran con los moros y judíos de Belorado ${ }^{17}$.

A fines del siglo XIII la judería de Belorado tributaba 8.500 maravedís, lo que podría corresponder a unas 13 familias con un total de unas 58 personas. Nuestra judería era, pues, mucho menor que las cercanas de Burgos o Pancorbo aunque también mucho mayor que las de Roa, Miranda de Ebro y Lerma.

Las luchas entre Pedro I y Enrique II resultaron revolucionarias para las juderías provinciales. Todas fueron diezmadas. Pero, mientras que las directamente dependientes de la corona (Burgos, Pancorbo y Miranda) seguían hundidas todavía un siglo después, las vinculadas a los Velasco (Belorado, Medina y Briviesca) superarían notoriamente a las anteriores, llegando a su más alta prosperidad. La de Belorado, en concreto, aparece en 1482, junto con la de Medina de Pomar, como la más numerosa y próspera de la provincia, en constante progreso hasta los días de la expulsión.

A mediados del siglo XIII, Fernando III recordaba que las aljamas

\footnotetext{
${ }^{16}$ F. FirA, «La aljama", pág. 6.

17 Ibid. $\mathrm{n}^{2} 5$.
} 
de la diócesis debían seguir pagando 30 dineros anuales a la iglesia de Burgos. Los 10.501 maravedís que nuestra judería pagaba en 1291 iban a parar a don Alfonso de Molina, Beltrán Ibáñez y don Manuel de Belorado, o sea don Simuel, recaudador arriba citado.

Al comenzar el siglo siguiente, Fernando IV permite que la villa cobre para sí los pechos que le entregaba la aljama, por cuanto los vecinos habían prestado a don Alfonso $\mathrm{X}$ cierta cantidad con el fin de reparar las murallas de Zamora ${ }^{18}$. En el mismo año concede también a Belorado la provisión de la escribanía a condición de que conservara la muralla por su cuenta y

"que fuese entregador de las debdas de los judios de ay de vuestro lugar, Mosen Ferin, mio dador" ${ }^{19}$.

Dos años más tarde ordenaba que los hebreos contribuyesen aparte de los cristianos.

Al fundar Enrique II cuatro capellanías en la catedral de Burgos por el alma de su hermano Sancho, fijó su pago (8.000 maravedís)

"en la cabeza de los pechos y derechos del concejo de Belorado y en la cabeza de los pechos y derechos del aljama de los judios de esta dicha villa, de los primeros y mejor parados".

Al año siguiente (1375) ordenaba a su contador mayor, Yuçaf Picho, que pagase a los frailes de San Francisco de la villa 3.000 maravedís como solía dárselos su hermano (Apéndice, $\mathrm{n}^{\circ} 2$ ).

En 1485 los judíos de Belorado pedían que se cumpliera la sentencia pronunciada en las disputas que sobre impuestos habían tenido con los lugares de Ezcaray y Valgañón. Dos años después el Consejo Real emplazaba a Abrayn Seneor para presentarse ante su tribunal a petición de la aljama que se decía agraviada por la cantidad que acostumbraba a entregar "desde mas de ochenta años" a la iglesia mayor de Burgos para que se cantase cada día una misa por el alma de don Sancho ${ }^{20}$.

18 L. Huidobro y F. Cantera, "Juderías", $\mathrm{n}^{\circ} 5$.

19 F. Blanco García, Belorado, pág. 143.

${ }^{20}$ F. Cantera confunde a este conde con el de la Castilla primitiva, lo que le induce a cometer el craso error de suponer la existencia de judíos en Belorado en el siglo XI. Véase R.G.S: T. IV, $\mathrm{n}^{\circ} 434$ y T. V, $\mathrm{n}^{\circ} 1.155$. Apéndices 2,3 y 4. 


\section{La administración de justicia. Pleitos}

En 1302 se firma una carta de concordia entre el concejo de la villa y la aljama de los judíos sobre el procedimiento que debían seguir estos últimos al reclamar sus deudas a los cristianos y las pruebas que debían aportar en justificación del pago de las mismas

"et el alcalde que los oya et que los judgue aquello que fallare que es fuero et derecho sin otro alongamiento ninguno... et si por aventura el conceio o el aljama sobre dichos pasasen o removiesen contra esto que sobre dicho es o contra parte dello en ningun tienpo que non sea oido nin vala. Et nos el conceio et el aljama sobredichos otorgamos e tomamos este fuero et esta abennencia sobre nos por todo tienpo".

Firman por parte hebrea

"don Semuel el Rali, don Senor et don Senor et Semuel don Hazan, don Harrach et don Yuzme hermanos, don Çag Varon, fijo de don... et Mosen et Yona su fijo et Salamon Sue...»"

En las Cortes de 1325 Alfonso XI mandaba que a los judíos de Belorado se les diese un juez propio que oyera sus causas exclusivamente, puesto que en adelante vivirían separados de los cristianos ${ }^{22}$. A fines del mismo siglo el rey ordenaba a su merino mayor que cualquier mandamiento ejecutorio que tuviese contra algún cristiano dado por los judíos de la villa, lo llevase a efecto pues había quejas de que no quería cumplirse ${ }^{23}$.

\section{Emplazamiento de la judería}

Es posible que cuando se reconstruye el pueblo y sus murallas, en tiempo de Alfonso $\mathrm{X}$, se obligase a los judíos a retirarse a un barrio especial. Explícitamente así se ordenó en 1325. Desde entonces la judería estaría emplazada en el "Corro", entre la torre del castillo, iglesia de Santa María y el sucio arroyo Verdancho.

\footnotetext{
21 Véase ibid., Apéndice 1.

22 F. FITA, «La aljama», n 2.

23 Ibid., $\mathrm{n}^{\circ} 4$.
} 


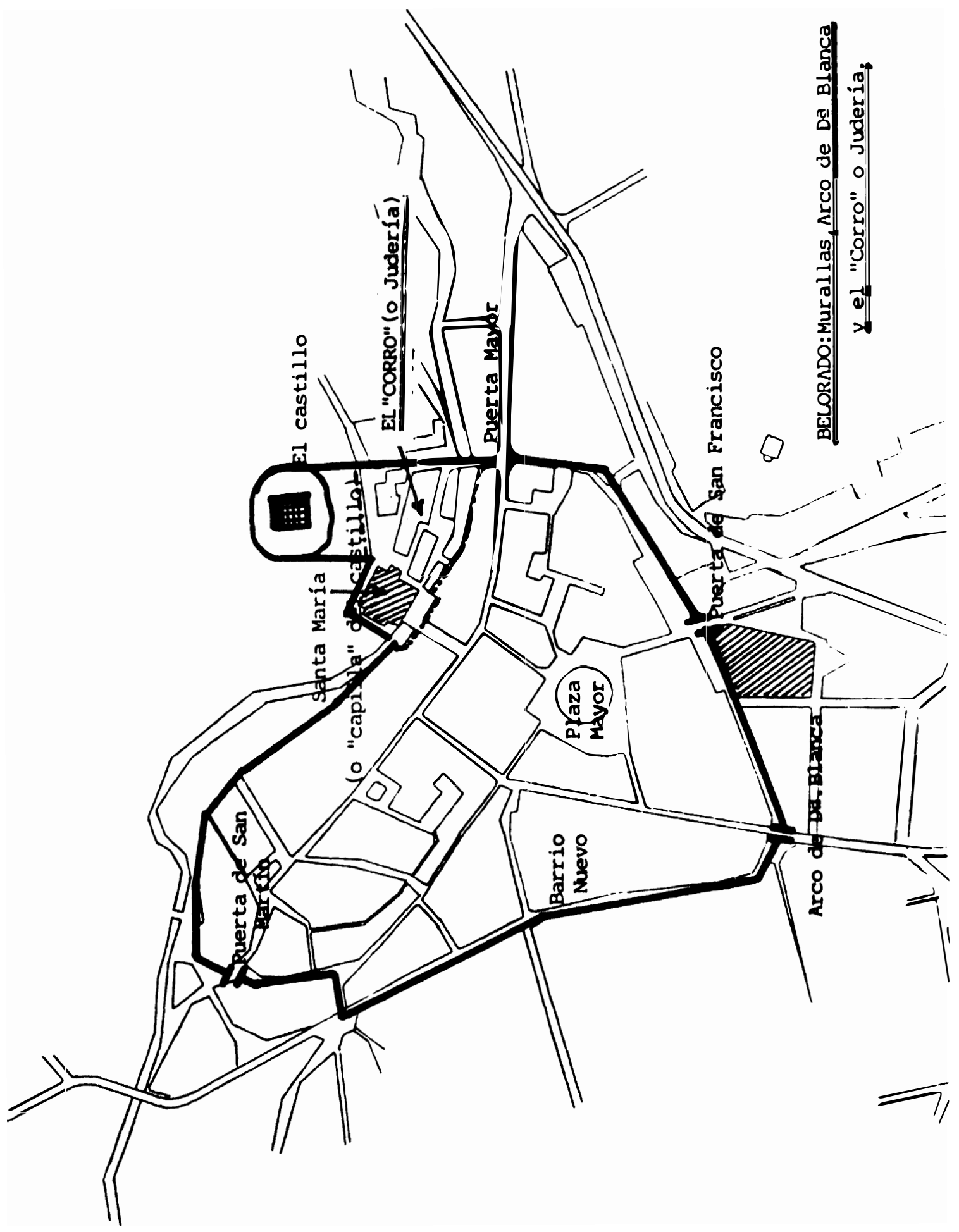


Luciano Huidobro asegura que el barrio hebreo se correspondió con lo que fue calle de San Martín, después Raimundo Miguel, en donde tuvieron hospital. Según Hipólito Bernal, habría que situarlo junto a la iglesia de San Nicolás, en la calle de los Castrillos ${ }^{24}$.

Sin embargo la documentación parece suficientemente clara como para rechazar ambas opiniones y emplazar la judería en el mencionado "Corro", barrio arrinconado, de tortuosas callejuelas y viviendas de pobres materiales, típico todo ello de las juderías peninsulares.

\section{LA MORERÍA}

A comienzos del siglo XIV se constata por primera vez la presencia de moros en Belorado. Pero, posiblemente, es mucho más antigua. Ya se han citado documentos en los que se les prohíbe entrar en el mercado y se les libra del pago de portazgo en todo el reino, lo que muestra su dedicación al comercio al igual que los judíos $\mathrm{y}$, lo mismo que éstos, se ocuparon también en la ganadería. Es muy posible que su actividad se extendiera a la construcción, como alarifes, como ocurrió frecuentemente en otras partes.

A fines del siglo XIV se les concede el privilegio (confirmado unos años después) de no tener que contribuir con los demás moros de las merindades de la Rioja y la Bureba ${ }^{25}$.

\section{OTRAS COMUNidADES hebreas Vinculadas A LA JUDERfa DE BELORADO}

«En este mesmo dia, mes y año (30-septiembre-1240) hallandose el rey Dn. Fernando en la ciudad de Cordova, informado que los judios de Burgos y su obispado no acudian cada uno a pagar a la yglesia de Burgos los treinta dineros que vendio Judas a Cristo, les mando por su real çedula que los pagasen como los auian pagado siempre a los obispos diocesanos y nombra y espresa en ella los de

\footnotetext{
${ }^{24} \mathrm{El}$ arrinconamiento junto al castillo, como en otros casos (Burgos, Nájera...), tendría como finalidad situar a los judíos en lugares apartados, resolver el problema del costoso mantenimiento de la fortaleza, asegurar su control en caso de rebelión contra el monarca (lo que nunca hicieron los judíos) y asegurar, también, su propia vida al terner un refugio en caso de ataque por parte cristiana.
}

${ }^{25}$ F. FITA, "La aljama», $n^{\circ} 5$. 
las sinagogas mayores del obispado de Burgos, que eran los de la mesma çiudad... Velorado... las cuales dice que los estauan sugetas otras muchas" ${ }^{26}$.

El número de las pequeñas que, tanto en el aspecto religioso como en el contributivo, dependieron de la sinagoga de Belorado, varía mucho a través de los tiempos. En 1290 aparece sola nuestra villa. En las diversas derramas del siglo XV se citan como dependientes suyas a Ojacastro, Valgañón, Villarta, Quintanar, Villadepero (Villapún-Castildelgado), San Vicente del Valle y Quintanilla San García; todas dentro de un reducido perímetro, pero todas también emplazadas en las principales vías de comercio con la Rioja. Una relación del 29 de abril de 1485 cita a todos los demás pueblos que aquí estudiamos, gravados con 109 castellanos "para ayuda de los gastos de la guerra de los moros» ${ }^{27}$. El número de lugares y el radio de influencia de la sinagoga de Belorado es mucho mayor, basculando ahora hacia Burgos aunque, como en el caso anterior, relacionados todos claramente con las vías más concurridas.

Finalmente hay que dejar cosntancia de cómo, a juzgar por los apellidos, la presencia (o emigración) de judíos de Belorado es constatable a través de la documentación en puntos muy distintos. A comienzos del siglo XV, por ejemplo, son varios los israelitas que viven en Zaragoza. En 1402 se cita a Azmel Bilforat, en 1420 a Abrahan Bilforat y en 1447 a León Bilforat, que bien podría corresponder a una sola familia. Dicha emigración podría deberse tanto a las persecuciones sufridas por la judería a fines del siglo XIV como al intenso comercio con el reino de Aragón y, especialmente, con su capital, a través de los pueblos riojanos cuyas aljamas antes hemos citado.

Arlanzón se encuentra en una de las vías hacia la Rioja. El Cuellavaga del documento antes citado creo que hay que identificarlo con el desaparecido lugar de Cuevagallegos, cerca de Pancorbo. Nada menos que en el año 1088 aparece en este pueblo un judío llamado Cit Iuda. Iscaray es el actual Ezcaray, lugar de la Rioja. En 1485 el Consejo Real ordenaba que se cumpliera la sentencia pronunciada sobre los debates que en materia de impuestos habían

${ }^{26}$ B.N: Ms. 13.122, fol. 216.

27 F. CANTERA, La judería de Miranda de Ebro (1099-1492), Miranda de Ebro 1987, pág. 104. 
tenido los judíos de Belorado con los del Val de Ezcaray y Valgañón. Por los días de la expulsión se ordenaba al bachiller Pero Pérez de Vicuña y al corregidor de Santo Domingo de la Calzada que entendieran breve y sumariamente en los pleitos que sobre deudas tuvieran las citadas aljamas con el fin de cumplir con el decreto de expulsión ${ }^{28}$.

Refresneda es, con bastante probabilidad, Fresneda de la Sierra Tirón y no Fresneña, a pesar de su cercanía a Belorado. En 1460 Enrique IV confirmaba diversos privilegios de sus antepasados a los hombres buenos del lugar para que los señores de estos lugares no les metieran por fiadores en deudas con cristianos y judíos ${ }^{29}$.

Galarde se encuentra junto al camino que conduce a Burgos. El extraño nombre de Hacheye, creo que hay que reducirlo a Agés, pueblo cercano al anterior, y no identificarlo, como hizo Baer, con el lejano lugar alavés de Fontecha.

Ojacastro es pueblo de la Rioja, cercano a Ezcaray. Unos meses después de la expulsión, los Reyes Católicos ordenaban al dueño de este último lugar que devolviera los bienes pertenecientes a la herencia paterna de Pedro Martínez de Valgañón y sus hermanos, judeoconversos de Ojacastro, pueblo en que los habían dejado al tiempo de su expulsión ${ }^{30}$.

Olmos, habrá que identificarlo con el actual Olmos de Atapuerca. Piedrahita, "çerca de Bilhorado", tendrá que ser Piedrahita de Juarros, a pesar de su relativa lejanía. Quintanilla San García es un pueblo al norte de Belorado, bastante retirado, por el que pasó una vía secundaria del camino de Santiago, que pudo atraer a alguna familia judía ${ }^{31}$.

Quintanar de Rioja está en el camino que une Castildelgado con Eterna. Aunque no citado en los documentos, también en San Miguel de Pedroso hubo judíos. En el año 1099 aparecen como testigos de cierto documento "ex iudeis... Naanias Maior testis, Naanias Minor testis, Cide testis». Otros lugares en los que consta que hubo aljamas fueron San Vicente del Valle, Santa María del

${ }^{28}$ R.G.S: T. IV, $\mathrm{n}^{\mathrm{e}} 434$ y T. IX, $\mathrm{n}^{\mathrm{e}} 1.889$.

29 F. Blanco García, Belorado, n² 122, pág. 108.

30 R.G.S: T. XII, $\mathrm{n}^{2} 3.185$.

${ }^{31}$ I. Cadiñanos Bardeci y E. Cadiñanos González-Nicolás, "El Camino de Santiago en Burgos, una vía secundaria y poco conocida", Diario de Burgos (13agosto-1989) pág. 26. 
Invierno, Santurde y Santurdejo; Nilanes (o Uilanos) podría reducirse a Silanes.

A fines del siglo XIII el rey don Sancho obligaba a los judíos de Valgañón, bajo amenaza de destierro, a dar posada a clérigos y justicias, cosa que no querían hacer. Antes ha sido citada la sentencia del pleito que enfrentó a la aljama de Belorado con las de Ezcaray y Valgañón por cuestión de impuestos y también cómo, al tiempo de la expulsión, se encomendó a ciertos personajes que conocieran con brevedad los pleitos que surgieran antes de su marcha. Todavía unos años después de dicha expulsión (1495) se emplazaba a don Luis de Velasco para que restituyera a Juan Martínez de Valgañón y a sus sobrinos, judeoconversos, unas casas que poseía en Belorado ${ }^{32}$.

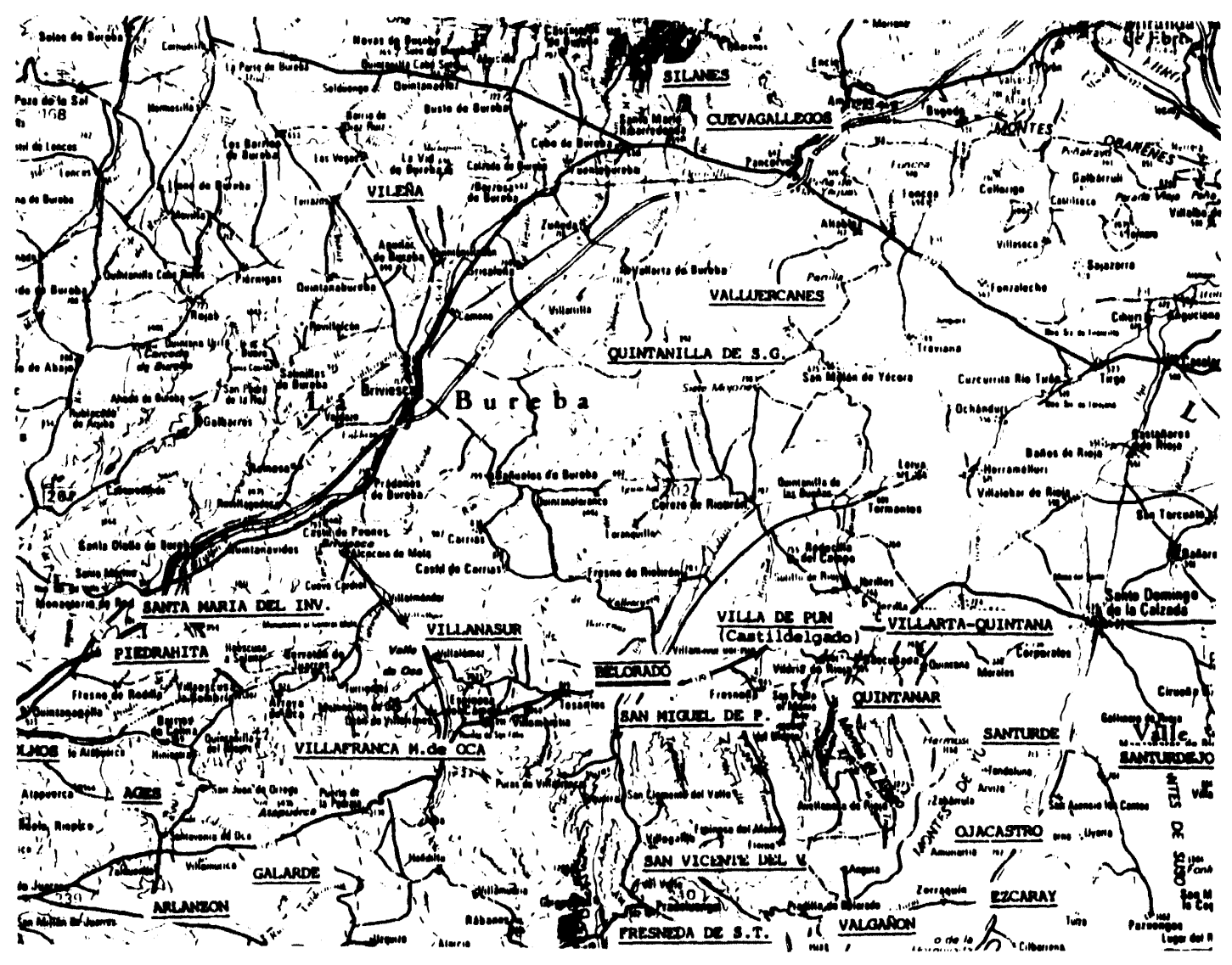

Aljamas relacionadas con la judería de Belorado

En Vileña (Beleña) aparece en 1315 un tal «Yago, judio». Vallorquinos es Valluércanes. Otros lugares con judería fueron Villafranca

32 R.G.S: T. XII, ne 3.227. 
Montes de Oca y sus aldeas, Villanasur de Río de Oca, Villa de Pon (hoy Castildelgado) y Villarta-Quintana, en la Rioja.

Hay tres pueblos cercanos a Belorado cuyas aljamas no dependieron de esta villa sino que fueron independientes, pero que a menudo los documentos las relacionan entre sí. Se trata de Cerezo de Río Tirón, Grañón (Rioja) y Redecilla del Camino. En 1488, por ejemplo, la justicia real ordenaba a los alcaldes de Belorado, Redecilla y otros, que prendieran a don Ça Aralte, judío vecino de Redecilla, por deudas habidas con cierto merino de Belorado. En 1492 consta que era recaudador de las alcabalas de Haro y Cerezo de Río Tirón, el judío Abrahan Arrute ${ }^{33}$.

\section{EXPULSIÓN Y CONVERSIÓN. El TRIBUNAL DE LA INQUISICIÓN}

Como en otros lugares, la rapidez de la expulsión trajo problemas de ajuste económico. Recordemos algunos documentos ya citados. Por los días del extrañamiento se ordenaba entender breve y sumariamente en los pleitos que por deudas tuvieran los judíos de Valdezcay y Valgañón, con el fin de cumplir el decreto de expulsión. Unos días después se comisionaba a cierto vecino de Burgos para que llevase a ejecución, en ciertos bienes de los judíos de Belorado y Briviesca, lo que éstos debían a don Juan de Ortega, obispo de Almería, por el arrendamiento de las rentas de la abadía de Foncea y provisoría de Villafranca, el cual temía no cobrarlo por el edicto de expulsión y no estar aún vencidos los contratos.

Pero tras la marcha también aparecieron problemas. En 1493 se comisionaba al corregidor de Burgos, a petición del subcolector apostólico de Palencia, que reclamaba las deudas que con él tenían unos judíos y que había traspasado, al tiempo de su expulsión, a ciertos labradores de Villafranca, Briviesca y Belorado. La nobleza fue la mayor beneficiada del destierro pues se hicieron, legal o forzosamente, con los bienes dejados ${ }^{34}$. En 1495 se obligaba al señor de Ezcaray, Pedro Manrique, a devolver ciertos bienes de unos judeoconversos de Ojacastro. Unos días después se hacía otro tanto con Luis de Velasco, señor de Belorado, para que devolviera unas casas de la villa ${ }^{35}$.

${ }^{33}$ Ibid., T. V, n² 2.527 y T. IX, $\mathrm{n}^{2} 703$.

${ }^{34}$ Ibid., T. X, $\mathrm{n}^{\mathrm{e}} 2.164$.

${ }^{35}$ Ibid., T. IX, n² $1.935 ;$ T. X, nos 1.889 y 2.164 ; T. XII, nos 3.185 y 3.227 . 
La rivalidad entre los tribunales de la Inquisición de Calahorra y Valladolid por la definitiva atribución de la zona de Montes de Oca, duró 20 años (desde 1540 a 1560). Quedó para la primera, seguramente tanto por su cercanía como por los tradicionales lazos económicos entre la Rioja y la Riojilla. En 1581 se ordenaba que las visitas de dicho tribunal en esta última región fueran realizadas periódicamente, puesto que ya eran muchos los años en que no se hacía. De todas maneras la actividad de la Inquisición a través de los siglos fue casi nula, lo que muestra una conversión hebrea y mudéjar sincera o, al menos, que la tolerancia local supo asimilar rápidamente a estas clases marginadas. Todavía quedan apellidos en Belorado que recuerdan la estancia y conversión de una rica colonia judía durante varios siglos, que, debido a una injusta ley, desapareció hace ahora 500 años.

\section{APÉNDICE DOCUMENTAL}

Carta de acuerdo sobre deudas entre el concejo y el aljama de la villa.

Arch. Munic. de Belorado. Carp. 2.012, nº 12.

In Dey nomine amen. Sepan quantos esta carta vieren commo sobre contienda que era entrel conceio de Bilforado e ... desse mesmo logar en razon de las debdas que deuen los christianos a los judios en que dicen los judios que se les alongauan las debdas por razon de las sennales. Et el conçeio e el aljama sobredichos vinieron a nos don Garcia Ferrandez de Villamayor, adelantado maior de Castiella, et por abenimiento de amas las partes acordaron e ordenaron todas estas cosas que aqui seran dichas. Primeramientre que las debdas de los judios non se demanden por sennales, e que quando algun judio o judia quisiere demandar su debda al christiano o a la christiana que morare en Bilforado o en sus aldeas que muestre la carta al juez o al merino de Bilforado que pusiere el conceio por si, que entregue las debdas de los judios e que vaya luego a casa del debdor o del fiador, e al que fuere raygado en quantia de la demanda o en cient maravedis de la moneda nueva gele tomen vn penno aquel que es de fuera $e$ que le pongan a tercera casa fasta tercer dia. Et si fasta tercer dia el debdor 
o el fiador quisiere dezir algunna buenna razon derecha sin alongamiento e sin malicia que cunpla de derecho sobre su raiz o sobre su mueble. Et el alcalde que los oia e que los judgue aquello que fallare que es fuero e derecho sin otro alongamiento ninguno e al que non fuere raigado que vaya otro con el judio o con la judia e que le pendren lo quel fallaren fasta en quantia de la debda e que le pongan a tercera casa fasta tercer dia. Et si entre tanto quisiere dar sobre cabador raigado de la pendra que gela den sobrecabada fasta tercer dia a que pueda decir lo que decir quisiere contra la debda asi commo sobredicho es. Et si fasta tercer dia non viniere o non vinieren decir ante el alcalde algunna razon buenna e derecha e sin malicia por si quedase adelante el juez o el merino que pendrar por la debda que uendan el mueble a nueue dias. Et la raiz a treynta dias asi commo es fuero. Et que entreguen de la debda al judio o a la judia sin otro alongamiento ninguno. Pero si aquel que fuere peindrado non fuere en la villa o fuere doliente, que el alcalde que le de aquel plazo que fallare que es de fuero a que pueda venir a decir contra la debda lo que quissiere asi commo sobredicho es. Et otrosi acordaron que para algunna demanda oviere el christiano contra el judio o el judio contra el christiano que sea sin carta aquel que oviere la demanda contra el otro que le faga enplazar o que le passe sennal para ante el alcalde. Et el alcalde que les libre aquello que fallare que es fuero. Et otrosi si alguno anparare peyndra al juez o al merino o quebrantre el testamiento que ellos ficieren que peche sesenta e çinco sueldos assi commo es fuero por cada vez que forçare la peyndra o quebrantre el testamiento. Et si para esto conplir mester ovieren ayuda que vaian los alcaldes e los jurados e el prestamero con ellos por que los judios ayan sus debdas bien conplidamiente asi commo sobredicho es. Et si por auentura el conceio o el aljama sobredichos pasasen o remouiesen contra esto que sobre dicho es o contra parte dello en algun tienpo que non sea oydo nin vala. Et nos el conceio e el aljama sobredichos otorgamos e tomamos este fuero e esta abenencia sobre nos por todo tienpo. Et ninguno que otro remouimiento ficiere por el conceio e por el aljama que non vala. Et si por auentura el juez o el merino non usaren bien de su ofiçio nos el conceio sobredicho que pongamos otro i. Otrosi lo que ovieren dauer el juez o el merinno por la entrega que ficieren que lo de aquel de quien ficiere la entrega. Et pedimos merçed al Rey nuestro sennor que nos lo captenga por sienpre jamas e lo mande captener. Et por que esto sea firme e estable para sienpre jamas, nos el conçeio e el aljama sobredichos mandamos a Diago Ferrandez escriuano publico de Bilforado que ficiese desta dos cartas partidas por abece e pusiesse en ellas su signo en testimonio. Et nos el conçeio e el aljama sobredichos por mas firmeça sobrepusiemos en ellas nuestros seellos de çera colgados. Desto son testigos rogados de amas las partes don Garcia Ferrandez de Villamayor, adelantado maior en Castiella, e Johan Gonzalez e Martin Perez de Çelada e Johan Gallego escribano de 
don Garcia Ferrandez e Garcia Perez de Villadiego, don Johan arcipreste e Johan Perez fijo de don Pedro Marin, Ferrant Perez Brauo, don Pascual, don ... e don Johan Marin capellanos. Et Gonzalo Roiz de Anguciana e ... Diaz e Nicolas Roiz fijo de don J. Roiz e firmante Gonzalo de Ryodonna e don Pascual e Nicolas Perez, alcaldes. Don Johan maestre, don Gilen de Vals firmante. Y. Peros don Semuel el Rali ... don Senor e don Senor e Semuel, don Hazan, don Harrach e don Yuzne, hermanos. Don Çag Varon, fijo de don ... e Mosen e Yona su fijo e Salamon Sue ... e otros omnes buennos e yo Diago Ferrandez ... A trece dias de marzo, era de mill e trecientos e quarenta annos.

1375, septiembre 30 (Toro)

"Alvalá o carta real del Rei Dn. Enrique II dirigida a Dn. Juzaf Pichon, su contador maior, para que pagase a los frailes de Sn. Francisco de la villa de Velorado la merced de 3.000 maravedis que tenia anualmente de su hermano el conde Dn. Sancho en la que se les confirma tambien esta gracia".

Archivo de los Duques de Frías, Leg. 33, $\mathrm{n}^{2} 1$.

Don Enrique por la gracia de Dios rey de Castiella, de Toledo, de Leon, de Gallizia, de Seuilla, de Cordoua, de Murçia, de Jahen, del Algarbe, de Algezira e señor de Molina, a uos don Yuçef Picho nuestro contador mayor e a qualquier o qualesquier que por nos o por vos cogen o recabdan o ayan de coger e de recabdar en renta o en fialdat o en otra manera qualquier, agora e de aqui adelante las rentas e pechos e derechos de los que fueron del conde don Sancho nuestro hermano, que Dios perdone, e a qualquier o qualesquier de uos que esta nuestra carta fuere mostrada o el treslado della signado de escriuano publico, salut e gracia. Sepades que los frayres de Sant Françisco de Bilforado tenian por merçed en cada año del dicho conde don Sancho tres mill maravedis. Et agora sabed que es le nuestra merçed de gelos mandar confirmar e que los aian este año de la era desta carta e de aqui adelante de cada año segunt que los auian del dicho conde et segunt mas cunplidamente en el nuestro preuillegio que les nos mandamos dar en esta razon se contiene. Et agora los dichos frayres pidieron nos merçed que por quanto cada año fasian grant costa en venir recabdar la quantia cada año a la nuestra corte, que le mandasemos dar nuestra carta para vos para que le feziesedes recudir con ellos este dicho año e dende en adelant de cada año por auer esta carta espeçial en esta razon. Et nos 
touiemoslo por bien, por que uos mandamos vista esta nuestra carta o el treslado della signado como dicho es, que recudades e fagades recudir a los dichos frayres de Sant Françisco de Vilforado o al que lo ouiere de recabdar por ellos con los dichos tres mill maravedis que hauian de auer este dicho año en la manera que dicha es e dende adelant en cada año. Et librargelos en las rentas e pechos e derechos de Vilforado que fueron del dicho conde e que gelos den a los plazos e en la manera que en el nuestro preuillegio que les nos mandamos dar en esta razon como dicho es, se contiene. Et non tomedes dellos otra carta nuestra espeçial en esta razon, que con el treslado desta nuestra carta e con su carta de pago mandamos que vos sean reçebidos en cuenta e non fagades ende al so pena de la nuestra merçed.

Dada en Toro treynta dias de setienbre era de mill e quatroçientos e treze años.

3

1485, marzo 2 (Valladolid)

Carta a petición de los judíos de Belorado sobre materia de impuestos.

R.G.S: T. IV, n 434.

Don Fernando e doña Ysabel por la gracia de Dios rey e reyna de Castilla, de Leon, de Aragon etc, a los alcaldes de la nuestra casa e corte e chançellias e a los alcaldes e otras justicias qualesquier de los logares de Valdescaray e Valgañon que son en la merindad de Rioja e a todos los corregidores e jueses e alcaldes e otras justisias qualesquier de todas las çibdades e villas e logares de los nuestros reynos e señorios asy a los que agora son como a los que seran de aqui adelante e a cada vno e qualquier de vos a quien esta nuestra carta fuere mostrada o el treslado della sygnada de escrivano publico, salud e gracia. Sepades que por (roto) e de los judios de la villa de Vilhorado nos fue fecha relaçion que entrellos de la vna parte e las aljamas de los dichos logares de Valdescaray e Valdañon fuera comprometido çiertos debates e contyendas que tenian sobre la cabsa de pechos que pagauan ellos al cabildo de la çibdad de Burgos e del seruiçio e medio seruiçio que a nos auian a dar e pagar en cada año e sobre las costas que raby de las aljamas repartya en cada año en manos e poder de raby Biya vesyno de Vilforado e de rabi Symuel Picao vesino de la villa de Escaray, los quales dieran sentencia en su fabor en que mandaran que pagasen en cada año çierta quantya de maravedis segund que mas largamente en la dicha sentencia se contiene, la qual dis que fue consentyda e 
amologada por amas las partes e que fasta aqui syenpre auian conplido lo en ella contenido fasta que agora nueuamente de poco tienpo a esta parte se han subtraydo e subtraen de non querer pagar lo contenido en la dicha sentencia poniendo a ellos escusas e dilaçiones non deuidas en lo qual auian resçibido e resçebian muy grande agrauio e daño suplicaron nos e pidieron nos por merçed çerca dello les mandasemos porueer e remediar con justiçia mandando los dar nuestra ... (roto).

Dada en la noble villa de Valladolid a dos dias del mes de março año del nasçimiento de nuestro señor Ihesuchristo de mill e quatroçientos e ochenta e çinco años.

1487, septiembre 4 (Burgos)

"Carta de enplazamiento para don Abrahen Senior e para otras personas».

R.G.S: T. V, $\mathrm{n}^{\mathrm{e}} 1155$.

Don Ferrando e doña Ysabel etc. A vos don Abrayn Senior jues mayor de las aljamas de los judios destos nuestros reynos de Castilla e a otras qualesquier personas a quien lo de yuso en esta nuestra carta contenido atañe o atañer pueda en qualquier manera e a cada vno de vos a quien esta nuestra carta fuere mostrada, salud e gracia. Sepades quel aljama de los judios de la villa de Belorado nos enbiaron faser relaçion por su petiçion disiendo que se presentaban e presentaron ante nos ... de çiertos agrauios e mandamientos que vos el dicho don Abrayn Señor les abeys fecho e faseys e a raby Vsal su procurador sobre çiertos debates quellos auian con los judios que bibian en la villa de Escaray e Valgañon e Santurde e Santurdejo, vasallos de Pero Manrique, sobre razon que los dichos judios que asy biben en los dichos logares dis que estan en vso e costunbre desde mas de ochenta años fasta oy de contribuyr e pagar en los dies mill maravedis quellos pagan en cada año a la yglesia mayor de Burgos e al dean e quatro capellanes porque cada misa cada dia por el anima del conde don Sancho defunto e estando el dicho vso e costunbre sy no pagaban lo que les esta repartido por ellos, dis que los prendia las personas e los bienes e dis que porque en vida del conde de Haro difunto reclamaban del dicho repartimiento e derrama e desian que non los cavian de pagar a cada vno lo que asy les era repartido dis que vino Pero Manrique defunto e Ladron de Leyba asy mismo defunto a el dicho conde de Haro e a su ruego dis que lo arbitraron en manos de juezes arbitros los quales dis que pronunçiaron sentencia e mandaron que los dichos judios que asy bibian en los dichos 
logares e los que bibiesen e viniesen a morar a ellos pagasen en cada año para syenpre jamas cada vno çierta quantia de maravedis en la cabeça de pecho e en el seruiçio e medio seruiçio que en cada año ellos pagan a nos, la qual dicha sentençia dis que ha que se pronunçio mas de trynta e dos años e que despues desto syenpre ha seydo e fue consentida e emologada e pagaron syn contradiçion alguna fasta agora que dis que con fabor de Pero Manrique su señor, se alçan e apartan de non querer contribuyr e pagar en la dicha cabeça de pecho de los dichos diez mill maravedis que asy ellos pagan en cada un año a la dicha yglesia mayor e al dicho dean e quatro capellanes della para que canten la dicha misa, de la qual dicha sentencia dis que teneis nuestra carta publica que sea guardada segund que en ella se contiene, e dis que los dichos judios non obstante lo susodicho se opusieron contra la dicha sentencia e conpromiso que fizieron ... $\mathrm{E}$ dis que ganaron cartas de vos el dicho don Abrayn Señor por las quales dis que los poneys penas de aladmas e de dies mill maravedis para la guerra de los moros que los dan por libres e quitos de la dicha sentencia e que todas las aljamas de veynte leguas alderredor de ... e dis que se probaran que han estado en vso e costunbre que los judios que han bibido e biben en los dichos logares e en todos los logares del dicho valle ser suscrydas para pagar la dicha cabesça de pecho abia estado otras villas que son Grañon e Redesilla del Camino e Val de Sant Biçente e Val de Riodon que todos los judios que bibian en ellas pagan en lo suso dicho e ... nos suplicaban e pedian por merçed ... les dar nuestra carta de ymbiçion para vos el dicho don Abrayn Señor que non conosiesedes de lo suso dicho ... e nos tovimoslo por vien.

Dada en la muy noble çibdad de Burgos a quatro dias del mes de setienbre año del nascimiento de nuestro señor Ihesuchristo de mill $\mathrm{e}$ quatrosyentos e ochenta e syete años.

1492, mayo 25 (Valladolid)

«Los judios de Valdezcaray».

R.G.S: T. IX, $\mathrm{n}^{\varrho} 1889$.

Don Fernando e doña Ysabel etc. A vos el bachiller Pero Perez de Vicuña corregidor de la çibdad de Santo Domingo de la Calçada e a vos el bachiller Vallejo, vesino de la dicha çibdad, e a cada vno de vos, salud e gracia. Sepades que por parte del aljama de los judios e personas syngulares de Valdescaray e Valgañon nos fue fecha relaçion por vna petiçion que en el nuestro consejo fue remitida disiendo que bien sabiamos como mandamos 
pregonar publicamente en estos nuestros reygnos que desde el primero dia del mes de mayo deste año de noventa e dos fasta tres meses primeros syguientes todos los judios e judias de qualquier hedad o condiçion que fuesen saliesen destos nuestros reygnos so grandes penas e que asi mismo dentro de los dichos tres meses tomaramos a ellos e a los otros judios e a sus bienes e fasyenda so nuestro seguro e anparo e defendimiento real e para que podiesen vender y enejenar los dichos sus bienes e fasyenda e faser dellos como de cosa suya propia segund que esto e otras cosas mas largamente en las prouisiones que sobrello mandamos dar o dimos, se contiene. E dis que algunos dellos han deuido e deven algunas debdas a personas e a otras personas e a asy mismo dis que les son deuidas a ellos muchas debdas asy por christianos como por judios o moros asý en las dichas villas de Ezcaray e Valgañon como en otras villas e logares comarcanos e dis que por las debdas que ellos deven han seydo e son mucho fatigados para que las paguen luego en la ora avnque los plazos dellas no sehan llegados e que las debdas que a ellos les son deuidas gelas non quieren pagar. A mas dis que gelas ponen a pleito sabiendo el termino que tenian que faran muy bien pensando que para no poner en peligro sus personas ... E que como quier que asy mismo que dan los tales bienes e que non los quiere resebir ... que si asy pasase non podrian conplir lo que por nos les esta mandado. E que a mas desto tienen dado bestias, mulas e otras cosas en fiado a algunas personas asy a christianos como a judios e lo tienen oy en dia en pie e gelo demandan agora para se aprouechar dello, dis que gelo non quieren dar nin entregar e que algunos dellos tienen conpradas casas e a otros heredamientos e a las tales personas para gelo prestar a çiertos plazos ... que pues ellos se han de yr destos nuestros reygnos e non pueden cunplir con ellos que les tornen las quantias de maravedis e otras cosas que les tienen escomençado a pagar e que reçiban las tales casas e heredamientos pues que non lo pueden lleuar consigo, dis que tanpoco lo han querido nin quieren faser poniendo a ello sus escusas non deuidas en lo qual todo dis que han resçebido e resçiben muchos agrauios e dapño ... por ende que nos suplicauan e pedian por merçed çerca dello les prouesemos de remedio con justiçia por manera que antes del dicho tienpo ellos ouiesen e cobrasen todo lo suyo e se podyesen yr ... lo qual visto en el nuestro Consejo fue acordado ... que llamadas e oydas las partes determinase lo que fuese justiçia...

Dada en la villa de Valladolid a veynte e çinco dias de maio de mill e quatroçientos e noventa e dos años. 


\section{RESUMEN}

La judería de Belorado, una de las más importatntes de la provincia de Burgos, llegó a su máximo esplendor bajo los duques de Frías. En este artículo se estudian las actividades y posesiones de los judíos de esta villa, su situación fiscal y la administración de justicia, hasta el momento de la expulsión. También se estudia el emplazamiento de la judería, que se conoce con el nombre del "Corro", así como la presencia de moros en la ciudad y la identificación de otras comunidades hebreas de la región vinculadas a Belorado. Se incluye un apéndice documental.

\section{SUMMARY}

The Jewish quarter of Belorado, one of the most important in the province of Burgos, reached its greatest magnificence under the Dukes of Frias. This article deals with the activities and properties of the Jews of that town, their fiscal conditions, and their juridical administration, up to the time of the expulsion. The site of the Jewish quarter, known as "Corro", is also studied, as well as the presence of Moors in the city and the identification of other Hebrew communities connected to Belorado. An appendix with the documents is included. 